\title{
Diversity and prevalence of gastrointestinal parasites with zoonotic potential of Green Monkeys in Bandia Reserve in Senegal
}

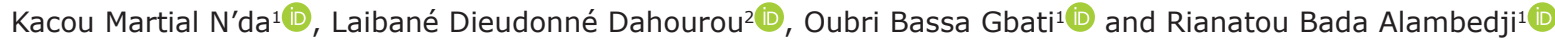

1. Department of Public Health and Environment, Inter-States School of Veterinary Sciences and Medicine (EISMV) of Dakar, BP 5077 Dakar, Senegal; 2. Institute of Environmental Sciences and Rural Development (ISEDR), University of Dedougou, BP 176 Dedougou, Burkina Faso.

Corresponding author: Kacou Martial N'da, e-mail: ndakacoumartial@gmail.com

Co-authors: LDD: d_dahourou@yahoo.fr, OBG: oubribassa@yahoo.fr, RBA: rianatoub@yahoo.fr

Received: 11-11-2020, Accepted: 02-02-2021, Published online: 06-03-2021

doi: www.doi.org/10.14202/IJOH.2021.65-69 How to cite this article: N'da KM, Dahourou LD, Gbati OB, Alambedji RB (2021) Diversity and prevalence of gastrointestinal parasites with zoonotic potential of Green Monkeys in Bandia Reserve in Senegal, Int. J. One Health, 7(1): 65-69.

\begin{abstract}
Background and Aim: Parasitic and infectious diseases are ubiquitous threats to primate and human populations. This study was carried out to study the diversity and frequency of gastrointestinal parasites with zoonotic potential in green monkeys in the Bandia Reserve located in Senegal.

Materials and Methods: For this study, 164 stool samples of Chlorocebus aethiops sabaeus (green monkey) were collected from October to November 2018 from Bandia Reserve. Stool samples were processed using the merthiolate-iodine-formalin staining technique and the modified Ritchie method. The slides were examined under a microscope and the identification of parasites was based on the morphology of protozoan cysts and helminth eggs. The analysis of data was conducted using $\mathrm{R}$ version 3.4 .3 with $\mathrm{p}=0.05$.
\end{abstract}

Results: A total of six species of parasites were found, including five protozoa (Entamoeba coli, Entamoeba histolytica/ dispar, Entamoeba hartmanni, Endolimax nana, and Iodamoeba butschlii) and one nematode (Strongyloides spp.). The overall prevalence of gastrointestinal parasite was 76.2\% (95\% CI: 69.7\%-82.7\%). Two parasites with zoonotic potential, mainly E. histolytica/dispar with a prevalence of 13.4\% (95\% CI: 8.2\%-18.6\%) and Strongyloides spp. with a prevalence of $6.7 \%$ (95\% CI: $2.9 \%-10.5 \%)$, were found.

Conclusion: This study indicated that the monkeys of the Bandia Reserve are infested by zoonotic parasites and can, therefore, ensure transmission to visitors to the Reserve. The parasitological data that we report are the first available for these species of monkeys in the Bandia Reserve.

Keywords: Bandia, Chlorocebus aethiops sabaeus, gastrointestinal parasites, Senegal, zoonotic parasites.

\section{Introduction}

Primates play an extremely important role in the balance of ecosystems as pollinators and also as seed dispersers. Likewise, primates are involved in the development of new drugs and treatments in human medicine. They are predators for some animal species and are also used as prey for wild carnivores [1]. Despite their important role in ecosystems, primates are increasingly threatened by human activities such as habitat modification, hunting, and illegal trade [2]. Current information shows the existence of 504 species and $\sim 60 \%$ of primate species are now threatened with extinction and $\sim 75 \%$ have declining populations [3]. To mitigate this extinction, other conservation alternatives have been considered and among them ex situ conservation through zoological parks and private reserves play an important role. The

Copyright: N'da, et al. This article is an open access article distributed under the terms of the Creative Commons Attribution 4.0 International License (http://creativecommons.org/licenses/ by/4.0/), which permits unrestricted use, distribution, and reproduction in any medium, provided you give appropriate credit to the original author(s) and the source, provide a link to the Creative Commons license, and indicate if changes were made. The Creative Commons Public Domain Dedication waiver (http:// creativecommons.org/ publicdomain/zero/1.0/) applies to the data made available in this article, unless otherwise stated. role of these reserves is to promote the sustainable development of fauna and to ensure the conservation of these species and their genetic heritage. This is the case with the largest private reserve in Senegal, namely, the Bandia Reserve, which plays a key role in species conservation.

However, this reserve has a restaurant which frequently attracts groups of green monkeys (Chlorocebus aethiops sabaeus) of the reserve. These monkeys often have close contact with tourists, workers, and other visitors to the reserve. Sometimes, monkeys steal visitors' food during their meals by introducing their hands in plates and also leave their stool on the catering table. This situation can be lead to transmission of gastrointestinal parasites to human as it is known that monkeys frequently harbor numerous pathogenic gastrointestinal parasites, often asymptomatically [4]. Entamoeba histolytica infection is estimated to kill more than 55,000 people each year. Globally, diarrheal disease is the third leading cause of death in children under 5 years of age with amebic colitis being a leading cause of severe diarrhea in low-income countries [5] and also Giardia duodenalis could cause serious health disorders in human. Other protozoa such as Blastocystis hominis and Dientamoeba fragilis also have 
pathogenicity and can be transmitted from primates to humans. Hymenolepis nana, Ancylostoma duodenale, and Strongyloides stercoralis are nematodes recognized parasites with zoonotic potential which can cause serious digestive disorders in humans if infection with these parasites is not treated quickly [6]. However, in the Bandia Reserve, no study has been implemented to study parasite of these monkeys.

This study aimed to study the diversity and frequency of gastrointestinal parasites with zoonotic potential in green monkeys in the Bandia Reserve, located in Senegal.

\section{Materials and Methods}

\section{Ethical approval}

The protocol of our study was examined and had the favorable approval of the Research Ethics Committee (CER) of the University Cheikh Anta Diop of Dakar.

\section{Study location and period}

The present study took place in the Bandia Reserve located in West Senegal (N 14' 33'539 and W $17^{\circ} 00$ ' 637). The reserve is located $65 \mathrm{~km}$ from Dakar between the new international airport and Saly Portudal, near the department of Mbour (Figure-1). Created in 1990 on the territory of the pre-existing classified forest of Bandia, this reserve covers 1500 hectares with a project to extend to 3500 hectares. It is a small jewel of ecological success with the regeneration of its flora and the reintroduction of large African mammals some of which have been extinct for centuries. Most of the animals are kept in semi-freedom mode. Apart from the large predators, some African mammals such as white rhinos (Ceratotherium simum), zebras (Equus zebra), giraffes (Giraffa camelopardalis), buffaloes (Syncerus caffer), Derby elands (Taurotragus derbianus), Cape elands (Taurotragus oryx), oryx (Oryx dammah), roan hippotragus (Hippotragus equinus), nyala (Tragelaphus angasii), defassa cobs (Kobus ellipsiprymnus defassa), Buffon cobs (Kobus kob), large kudu (Tragelaphus strepsiceros), impalas (Aepyceros melampus), dama gazelles (Nanger dama), red-fronted gazelles (Eudorcas rufifrons), warthogs (Phacochoerus africanus), jackals (Canis aureus), mongooses (Herpestes edwardsii), patas monkeys (Erythrocebus patas), green monkeys (C. aethiops sabaeus) and also crocodiles (Crocodylus porosus), giant tortoises (Chelonoidis nigra), ostriches (Struthio camelus), as well as more than 120 species of birds are found in this reserve. The green monkeys divided into different groups which are living free and with the possibility outside the reserve. The study was conducted from October to November 2018.

\section{Sampling}

Our work consisted of collecting stools from green monkeys in the Bandia Reserve for a coprological examination for helminths and possible amoebae. Based on the literature and the presence of gastrointestinal parasites in the feces of primates, the sampling was calculated with an expected prevalence of $90 \%$.

The following sample size calculation formula was used: $\mathrm{n}=\mathrm{t}^{2} \mathrm{xp}(1-\mathrm{p}) / \mathrm{m}^{2}$.

not $=$ Sample size required; $\mathrm{t}=95 \%$ confidence level (typical value of 1.96).

$\mathrm{p}=$ Estimated prevalence $(90 \%) ; \mathrm{m}=$ precision of $5 \%$.

Thus, a minimum sample of 138 stools was required for this study. To increase the precision of our results, a total of 164 stool samples from green monkeys were taken. Stool samples were collected in each group of green monkeys only once during our stay. For each group, stools sample were collected from

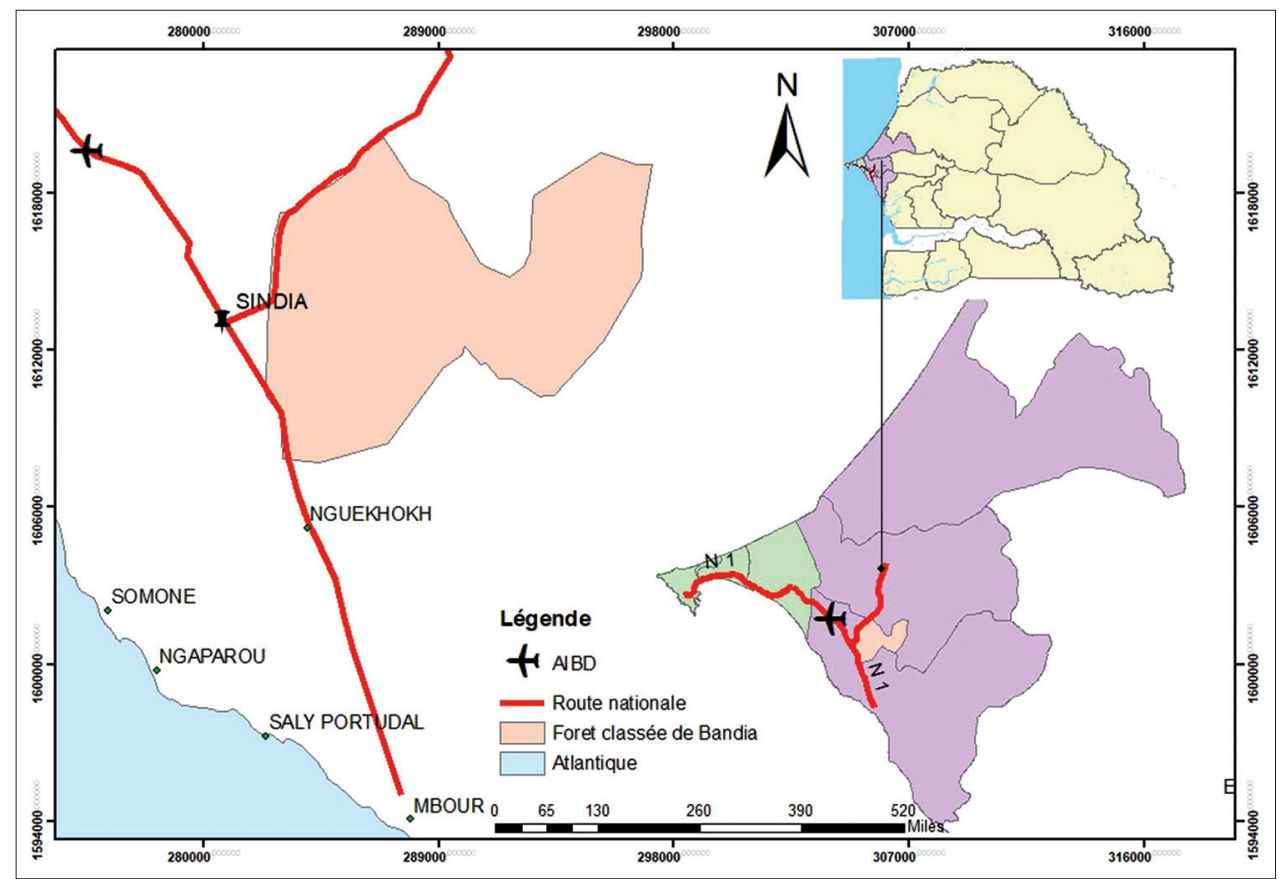

Figure-1: Geographical location of the Bandia Reserve [Source: Map generated by Kacou Martial N'da with the help of ArcGIS software]. 
most of the group individuals and we ensured that the sample was taken from each individual only 1 time.

\section{Field and laboratory procedure}

During the study period, fecal samples from the monkeys were collected between 8 a.m. and 6 p.m. During the sampling, 164 fecal samples were collected from these primates. To avoid contamination, fecal samples were taken from the center of each fecal mass immediately after defecation of the animals and then placed individually in sterile $60.0 \mathrm{~mL}$ vials with $10 \%$ formalin solution for storage. Each sample was analyzed by a parasite concentration method called the Ritchie method. This method is helpful to diagnose helminths and protozoa [7]. In addition to the previous method, we carried out a second analysis of each sample by the merthiolate-iodine-formal (MIF) staining method. This last method is easy to use and provides an enriching solution for all parasites, as well as it is very suitable for the amoeba diagnosis [7]. Eggs and cysts were detected under a microscope (Leica DM500 LED) equipped with a digital camera control unit. The parasites were identified on the basis of shape, size, color, content, and cysts. Representatives of each parasite were photographed.

\section{Statistical analysis}

The data from the coproscopic analyses were entered into a Microsoft ${ }^{\circledR}$ Office Excel spreadsheet under Windows 2013 then transferred to $\mathrm{R}$ software version 3.4.3 (https://www.r-project.org/Licenses/) to perform statistical analyzes and calculate confidence intervals. The Chi-square test was used to compare the infection status obtained after using the Ritchie method and the MIF staining technique. The chosen materiality threshold is set at 5\%. The result was significant if $\mathrm{p}<0.05$.

\section{Results}

\section{Identification of pests and global infestation}

After analysis of the 164 samples, a total of six species of parasites were found in the green monkeys of the Bandia Reserve. These are Strongyloides spp., E. histolytica/dispar, Entamoeba coli, Iodamoeba butschlii, Endolimax nana, and Entamoeba hartmanni (Figure-2). Of the 164 samples analyzed, 125 were positive for at least one parasitic species with a prevalence of $76.2 \%$ (95\% CI: $69.7 \%-82.7 \%)$. However, among the positive samples, 44 were polyinfested with a prevalence of $32.5 \%(95 \% \mathrm{CI}$ : $25.4 \%-39.6 \%$ ).

\section{Prevalence of parasites with zoonotic potential}

After treatment of the stool samples of the green monkeys by the Ritchie method and staining with MIF, two zoonotic parasites were found in their stool. These are the protozoan E. histolyticaldispar with a prevalence of $13.41 \%$ (95\% CI: $8.21 \%-18.61 \%)$ $\pm 5.2 \%$ and the helminth Strongyloides spp. with a prevalence of $6.7 \% \pm 3.8 \%$ (95\% CI: $2.9 \%-10.5 \%$ ).

\section{Parasitic indices of non-pathogenic parasites}

The study noted the presence of other non-zoonotic parasites in the samples after analysis. It is $E$. coli, I. butschlii, E. nana, and E. hartmanni with prevalences of $54.27 \%$ (95\% CI: 46.67\%-61.87\%) $\pm 7.6 \%$; $16.46 \%$ (95\% CI: $10.86 \%-22.06 \%) \pm 5.6 \% ; 12.19 \%$ (95\% CI: 7.19\%-17.19) $\pm 5.0 \%$; and 10.98\% $(95 \%$ CI: $6.28 \%-15.68 \%) \pm 4.7 \%$, respectively, as shown in Table-1.

\section{Comparison of the coprological methods used}

The use of the two coproscopic methods, that is, Ritchie method and MIF staining, made it possible to adjust the overall result of the study (Table-2). For this

Table-1: Prevalence of low pathogenic protozoa identified in the green monkeys of the Bandia Reserve.

\begin{tabular}{lcc}
\hline Parasites & $\begin{array}{c}\text { Positive } \\
\text { samples }\end{array}$ & $\begin{array}{c}\text { Prevalence (\%) } \\
\text { and 95\% CI }\end{array}$ \\
\hline Entamoeba coli & 89 & $54.3(46.7-61.9)$ \\
Iodamoeba butschlii & 27 & $16.5(10.9-22.1)$ \\
Endolimax nana & 20 & $12.2(7.2-17.2)$ \\
Entamoeba hartmanni & 18 & $11.0(6.3-15.7)$ \\
\hline
\end{tabular}

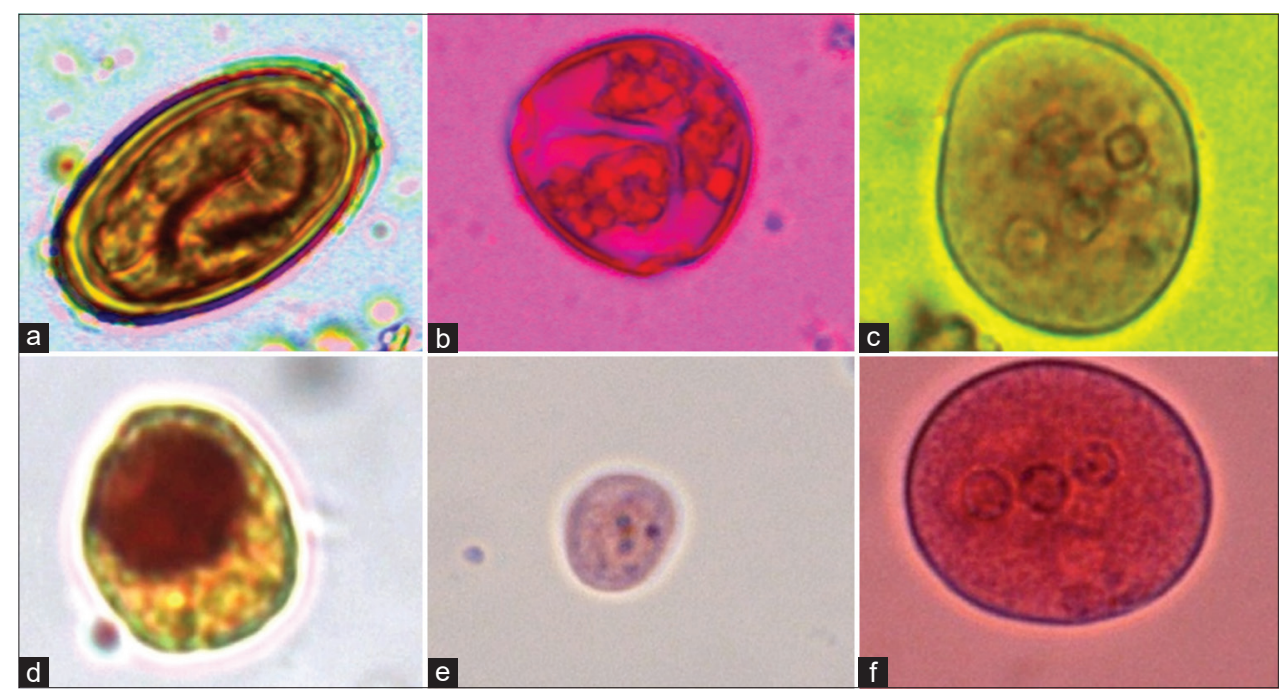

Figure-2: Parasites found in the monkeys of the Bandia Reserve: (a) Strongyloides spp., (b) Entamoeba histolytica/dispar, (c) Entamoeba coli, (d) Iodamoeba butschlii, (e) Endolimax nana, and (f) Entamoeba hartmanni (40x). 
Table-2: Comparison of data obtained by the two analysis techniques.

\begin{tabular}{lccc}
\hline Parasites & Ritchie method & Merthiolate-iodine-formal method & p-value \\
\cline { 2 - 3 } & \multicolumn{2}{c}{ Prevalence and 95\% CI } \\
\hline Protozoan & $37.19 \pm 7.3$ & $39.02 \pm 7.4$ & $5.3 \times 10^{-5}$ \\
Entamoeba coli & $5.49 \pm 1.7$ & $9.15 \pm 4.4$ & 0.16 \\
E. histolytica/dispar & $4.26 \pm 3.09$ & $15.24 \pm 5.5$ & $2.3 \times 10^{-5}$ \\
Iodamoeba butschlii & $5.49 \pm 1.7$ & $7.93 \pm 4.1$ & 0.1 \\
Endolimax nana & $6.1 \pm 3.6$ & $5.49 \pm 1.7$ & 0.03 \\
Entamoeba hartmanni & $6.71 \pm 3.8$ & 0 & $<2.2 \mathrm{e}-16$ \\
Helminth & & 0 & \\
Strongyloides spp. & & & \\
\hline
\end{tabular}

study, the helminth parasite has not been found using MIF technique. However, except for E. hartmanni, the prevalence of all other protozoan parasites was significantly higher using MIF than Richie method $(\mathrm{p}<0.05)$.

\section{Discussion}

Our results provide valuable information for the study of parasites in green monkeys in Senegal. We found zoonotic parasites which could potentially be shared between monkeys and human. Our analyses reveal a high prevalence and gastrointestinal parasites in the green monkeys of the Bandia Reserve. Out of 164 samples from green monkeys, 125 were positive, with an overall prevalence of $76.2 \%$. This high prevalence could be linked to the social structure of green monkeys and interactions with other groups of mammals, encounters especially in feeding areas and risky behaviors such as delousing accompanied by ingestion of parasites taken from the genital are [8]. A similar study carried in Taï National Park (Côte d'Ivoire) on seven Cercopithecidae, shows a fairly high prevalence of infestations of these different species of primates which varies between $65.22 \%$ and $86.96 \%$ [7]. This high prevalence compared with our findings could be linked to the climatic conditions of the study area, and particularly the temperature and humidity, favorable to the development of free infesting stages, especially since the samples were taken at the end of the rainy season in Bandia.

A total of six species of parasites have been found in animals, unlike other studies carried out by some authors in primates who found 12 species of parasites in Rubondo National Park (PN) in Tanzania [9]. Thirteen species of parasites have been identified in Mahale NP in Tanzania [10], and 14 species of parasites have been found in monkeys of the Kibale Forest in Uganda [11,12]. In these studies, species of trematodes and cestodes were also found. This is most likely linked to the fact that the trematodes and the majority of cestodes, with the exception of H. nana, need intermediate hosts, absent in the Bandia Reserve.

Among the six species of parasites, two were zoonotic, which are E. histolytica/dispar and Strongyloides spp., respectively, with a prevalence of $13.41 \% \pm 5.2 \%$ and $6.7 \% \pm 3.8 \%$. Indeed, several similar studies carried out in primates show the presence of these zoonotic parasites in the stools of primates [13-15]. Non-human primates are known to be the main hosts of $S$. stercoralis and, in particular, Strongyloides fuelleborni. Monkeys become infected by ingestion of food or water contaminated by parasites or by skin penetration by infectious third instar larvae [16,17]. During a massive infestation with Strongyloides, severe gastroenteritis, hepatitis, pneumonia, and myocarditis appear in both primates and humans [18]. Mortalities can be observed if adequate treatment is not carried out. As regards E. histolytical dispar, contamination is only carried out orally, following ingestion of cysts which have retained their infectivity potential. In the event of an infestation, it is possible to observe chronic colitis which is sometimes bloody, the course of which is generally fatal in primates than in humans [19]. In Côte d'Ivoire, the previous studies recorded a high prevalence of intestinal parasitic infestations during research on intestinal parasites in rural populations living near Tai National Park. Indeed, this study demonstrated presence of 21 parasites, including 10 with zoonotic potential [20]. These are among others certain parasites such as E. histolytica/dispar, S. fuelleborni, S. stercoralis, and G. duodenalis.

As monkeys share space with human in this reserve, mainly in the restaurant, this situation could be risky for visitor as parasite transmission could occur.

In the study, the other parasites found were amoeba and E. coli, I. butschlii, E. nana, and E. hartmanni have been identified in monkey stool. Amoeba is common in non-human primates which are a wellknown reservoir [8]. Protozoa, in particular amoeba, are parasites which most often infest primates [15]. E. coli had the highest rate among the parasites diagnosed with a prevalence of $54.27 \% \pm 7.6 \%$. In fact, E. coli is the usual and most widespread parasite in primates [4]. However, the description of these parasitic agents should not be neglected even if they are qualified as low pathogenic. They could, nevertheless, be shared between primates and humans.

\section{Conclusion}

Our study provides basic data on gastrointestinal parasites of green monkeys living in freedom in the 
Bandia Reserve. More specifically, we are providing firsthand information on these populations of primates that rub shoulders with visitors to the Bandia Reserve in Senegal. During our study, six parasites were identified, two of which were zoonotic. These are Strongyloides spp. and E. histolytica. The monkeys of the Bandia Reserve are thus infested by zoonotic parasites and can, therefore, ensure transmission to visitors to the reserve. This study could further shed light on above-mentioned zoonoses to prompt further action and control strategies.

\section{Authors' Contributions}

OBG, KMN, RBA, and LDD designed the study. KMN and OBG performed the research. KMN analyzed the data and interpretation. All authors have read and approved the final manuscript.

\section{Acknowledgments}

This work was supported by the United States Agency for International Development (USAID) Emerging Pandemic Threats 2 Programm through the One Health Workforce (OHW) project (Award number AID -OAA-15-00014) and implemented by One Health Central and Eastern Africa (OHCEA). The content is the responsibility of the authors and does not necessarily reflect the views of USAID.

\section{Competing Interests} interests.

The authors declare that they have no competing

\section{Publisher's Note}

Veterinary World (Publisher of International Journal of One Health) remains neutral with regard to jurisdictional claims in published map and institutional affiliation.

\section{References}

1. Audrey, C. (2017) Pourquoi Faut-il Sauver les Singes. Available from: https://www.20minutes.fr/planete/199886720170119-pourquoi-faut-sauver-singes. Retrieved on $11-08-2020$

2. Alejandro, E., Paul, A.G., Anthony, B.R., Christian, R., Eduardo, F.D., Anthony, D.F., Anne-Isola, K.N., Vincent, N., Eckhard, W.H., Joanna, E.L., Francesco, R., Claudia, B., Joanna, M.S., Thomas, R.G., Russell, A.M., Luis, V.A., Miguel, D.G., Sidney, G., Ricardo, D., Sam, S., Noga, S., Sarah, A.B., Agustin, F., Katherine, C.M., Katherine, R.A., Andreas, L.S.M., Serge, W., Robert, W.S., Ruliang, P., Inza, K. and Baoguo, L. (2017) Impending extinction crisis of the world's primates: Why primates matter. $S c i$. $A d v$., 3(1): e1600946-18.

3. Lacoste, R. (2009) Les Parasites Intestinaux Chez le Macaque Crabier (Macaca fascicularis): Etude Expérimentale et Recommandations Pour la Diagnose et la Gestion des Rhizoflagelles et Des Ciliés. National Veterinary School, Alfort. p230.

4. Sandor, C. (2019) Les Diarrhées Chroniques Chez les Primates Non Humains: Étude de cas de Diarrhées Chroniques Idiopathiques Chez le Macaque Rhésus
(Macaca mulatta). National Veterinary School of Toulouse, Toulouse. p185.

5. Swagata, G., Jay, P. and Shannon, M. (2019) Tissue destruction caused by Entamoeba histolytica parasite: Cell death, inflammation, invasion, and the gut microbiome. Curr. Clin. Microbiol. Rep., 6(1): 51-57.

6. Poirier, P. (2014) The intestinal parasite Blastocystis: Epidemiology and clinical importance. Lett. Infectiol., 29(2): 72-78.

7. Kouassi, R., McGraw, S.W., Kouassi, P., Boubacar, A., Brunet, J., Pesson, B., Banfoh, B., N'goran, E.K. and Candolfi, E. (2015) Diversity and prevalence of gastrointestinal parasites in seven non-human primates of the Tai National Park, Côte d'Ivoire. Parasite, 22: 1-12.

8. Diouck, D. (1999) Adaptations aux Modifications du Milieu des Colobes bais (Colobus badiustemmincki) de la forêt de Fathala, Parc National du Delta du Saloum, Sénégal. Cheikh-Anta-Diop University, Dakar. p158.

9. Petrášová, J., Modry, D., Huffman, M.A., Mapua, M.I., Bobáková, L., Mazoch, V., Singh, J., Kaur, T. and Petrželková, K.J. (2010) Gastrointestinal parasites of indigenous and introduced primate species of Rubondo Island National Park, Tanzania. Int. J. Primatol., 31(5): 920-936.

10. Kooriyama, T., Hasegawa, H., Shimozuru, M., Tsubota, T., Nishida, T. and Iwaki, T. (2012) Parasitology of five primates in Mahale Mountains National Park, Tanzania. Primates, 53(4): 365-375.

11. Gillespie, T.R., Greiner, E.C. and Chapman, C.A. (2004) Gastrointestinal parasites of the guçons of Western Uganda. J. Parasitol. Res., 90(6): 1356-1360.

12. Gillespie, T.R, Greiner, E.C. and Chapman, C.A. (2005) Gastrointestinal parasites of the colobus monkeys of Uganda. J. Parasitol. Res., 91(3): 569-573.

13. Gillespie, T.R., Lonsdorf, E.V., Canfield, E.P., Meyer, D.J., Nadler, Y., Raphael, J., Pusey A.E., Pond, J., Pauley, J., Mlengeya, T. and Travis, D.A. (2010) Demographic and ecological effects on patterns of parasitism in eastern chimpanzees (Pan troglodytes schweinfurthii) in Gombe National Park, Tanzania. Am. J. Phys. Anthropol., 143(4): 534-544.

14. Bi, T.D.T., Yapi, A., Acapovi, Y.G.L. and Soro, S.D. (2015) Inventory of digestive parasites in primates at the Abidjan National Zoo: Evaluation of the effectiveness of four methods of coprological diagnosis. Rev. Ivoir. Sci. Technol., 25(1): 204-217.

15. Dahourou, L.D., Gbati, O.B., Nacanabo, I., Diatta, C. and Pangui, L.J. (2017) Gastrointestinal parasitism in wildlife at Hann Zoological Park in Senegal. Rev. Elev. Med. Vet. Pays Trop., 70(1): 25-28.

16. Gillespie, T.R. and Chapman, C.A. (2006) Prediction of parasite infection dynamics in primate metapopulations based on attributes of forest fragmentation. Biol. Conserv., 20(2): 441-448.

17. Viney, M.E. and Lok, J.B. (2007) Strongyloides spp., Worm Book, the C. elegans Research Community. WormBook, Available from www.wormbook.org. Retrieved on 22-02-2021.

18. Toma, H., Sato, Y., Shiroma, Y., Kobayashi, J., Shimabukuro, I. and Takara, M. (2000) Comparative studies on the efficacity of three anthelmintics on treatment of human strongyloidiasis in Okinawa, Japan. Southeast Asian J. Trop. Med. Public Health, 31(1): 147-151.

19. Nozais, J.P., Datry, A. and Danis, M. (1996) Traité de Parasitologie Médicale. Vol. 21. Pradel, Paris. p186-191.

20. Roland, K.W.Y., Sylvie, P., Fidèle, B.K. and Hilaire, B.K. (2019) Parasites Gastro-intestinaux des populations humaines du parc national de Taï, Côte d'Ivoire. Eur. Sci. J., 15(36): $27-44$ 